\title{
Enhancing Metal-binding with Noncanonical Coordinating Amino Acids
}

\author{
Luca Sauser and Michal S. Shoshan*
}

\begin{abstract}
More than $50 \%$ of proteinogenic amino acid sidechains can bind metal ions, enabling proteins and peptides to bear these ions as cofactors. Nevertheless, post-translational modifications and incorporation of noncanonical amino acids bestow peptides and proteins myriads of other coordination capabilities, thanks to an enhanced metal binding. Here we summarize selected examples of natural and artificial systems that contain one or more noncanonical amino acids coordinating a metal ion and subsequently achieve a new or enhanced function. We report on a wide array of systems: from disease-related proteins that undergo sulfurylation or phosphorylation through natural metallophores that selectively capture precious essential ions to synthetic selfassembly strategies, biocatalysts, and chelating agents against toxic metals. Regardless of their (bio)synthetic routes, all possess unique metal-binding properties that could not be effectively achieved by systems composed of canonical residues.
\end{abstract}

Keywords: Metal-binding · Noncanonical amino acids $\cdot$ Nonribosomal peptides $\cdot$ Peptide siderophores $\cdot$ Posttranslational modifications

Numerous life processes depend on an intricate interplay between biomolecules and metal ions. In particular, proteins utilize various metal ions for multiple functions, where they serve as catalytic centers or aid in gaining appropriate folding. For these processes to occur in an orchestrated manner, proteins possess well-defined metal-binding sites that often exhibit high affinity and selectivity for a specific metal ion. ${ }^{[1,2]}$ These characteristics are achieved by amino acid (AA) sequences that act as ligands and constitute the first coordination sphere. In most cases, these metal-binding sites are established by canonical AAs that are ribosomally synthesized into peptides and proteins and give rise to a plethora of different metal-specific sequences. Nonetheless, post-translational modifications (PTMs) and nonproteinogenic AAs introduced synthetically or by nonribosomal peptide synthetases (NRPS) are found to enhance metal-binding properties. ${ }^{[3,4]}$ Herein, we summarize key examples of such unique functionalities harnessed both in natural and artificial systems (Fig. 1, Table 1).

\section{Naturally Occurring Modifications}

In various natural systems, noncanonical AAs (ncAAs) and PTMs are placed within peptidic scaffolds natively to intensify metal selectivity and affinity. These chemical transformations endow the peptides myriads of binding capabilities that are above and beyond those of the proteinogenic building blocks.

\subsection{Sulfurylation and Phosphorylation}

Sulfurylation and phosphorylation are the most common examples of PTMs that significantly alter metal binding in natural proteins and are, in certain cases, even suggested to be a part of specific disease mechanisms.

*Correspondence: Dr. M. S. Shoshan, E-mail: michal.shoshan@chem.uzh.ch Department of Chemistry, University of Zurich,

Winterthurerstrasse 190, CH-8057, Zurich, Switzerland

www.shoshangroup.com
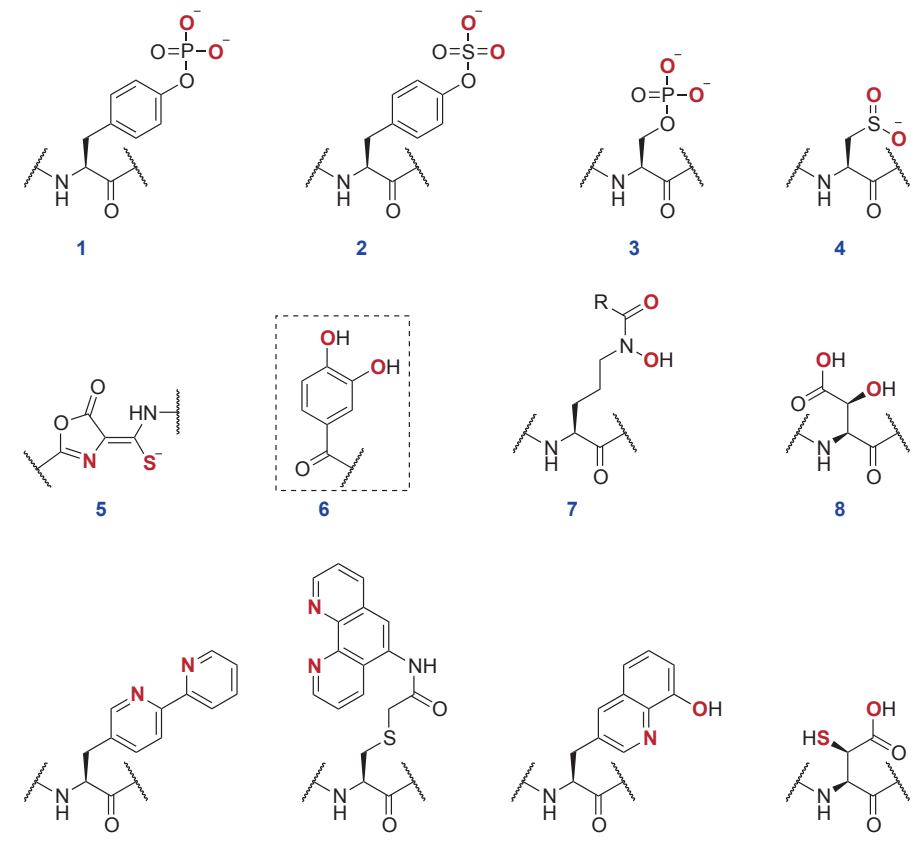

9

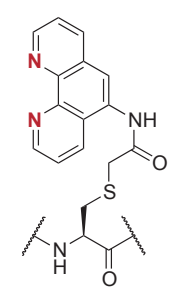

10
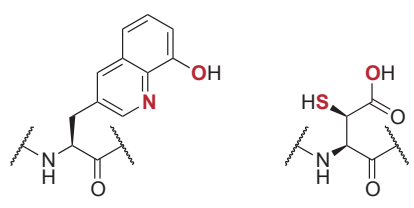

11

12

Fig. 1. Metal-coordinating noncanonical AAs (ncAAs) described herein. Binding atoms are marked in red. Moiety 6 is not derived from an AA but is highly abundant in metal-binding peptides.

\subsubsection{Cholecystokinin}

The effect of tyrosine (Tyr, Y) modification on metal binding in the hormone cholecystokinin (CCK) was demonstrated using the model octapeptide $\underline{D Y} M G W M \underline{D F}-\mathrm{NH}_{2}(\mathrm{CCK} 8)^{[5]}$ and its sulfurylated and phosphorylated analogs. ${ }^{[6]}$ Unlike the wildtype (WT) species, the modified peptides were found to bind an additional $\mathrm{Fe}^{3+}$ ion, increasing the binding capabilities of the ligand to a binuclear complexation. Structural elucidation of the complexes suggested that in the sulfurylated analog, the sulfate group is incapable of solely binding the second $\mathrm{Fe}^{3+}$ ion and ad- 
Table 1. ncAAs described herein

\begin{tabular}{|c|c|c|c|c|c|}
\hline & Name & Original AA & Modification & Metal ions & Examples \\
\hline 1 & pTyr (or pY) & Tyr & Phosphorylation & $\begin{array}{l}\mathrm{Fe}^{3+} \\
\mathrm{Tb}^{3+}\end{array}$ & $\begin{array}{l}\text { Cholecystokinin, } \\
\alpha-\text { Synuclein }\end{array}$ \\
\hline 2 & sTyr (or sY) & Tyr & Sulfurylation & $\mathrm{Fe}^{3+}$ & Cholecystokinin \\
\hline 3 & pSer (or pS) & Ser & Phosphorylation & $\begin{array}{l}\mathrm{Fe}^{3+} \\
\mathrm{Tb}^{3+} \\
\mathrm{Zn}^{2+}\end{array}$ & $\begin{array}{l}\alpha \text {-Synuclein, } \\
\text { Amyloid- } \beta\end{array}$ \\
\hline 4 & Cys-SO ${ }_{2}^{-}$ & Cys & Oxidation & $\mathrm{Tb}^{3+}$ & $\mathrm{CaM}$ \\
\hline 5 & $\begin{array}{l}\text { oxazolone- } \\
\text { thioamide }\end{array}$ & Ser and Cys & $\begin{array}{l}\text { Oxidation and } \\
\text { rearrangement }\end{array}$ & $\mathrm{Cu}^{+}$ & Methanobactin \\
\hline 6 & Catechol $^{\mathrm{a}}$ & - & - & $\mathrm{Fe}^{3+}$ & $\begin{array}{l}\text { Fuscachelin A, } \\
\text { Alterobactin A, } \\
\text { and B }\end{array}$ \\
\hline 7 & $\mathrm{ahOrn}^{\mathrm{b}}$ & Orn & $\begin{array}{l}\text { Acylation and } \\
\text { hydroxylation }\end{array}$ & $\mathrm{Fe}^{3+}$ & $\begin{array}{l}\text { Ornibactin, } \\
\text { Ferrichrome, } \\
\text { Attinimicin }\end{array}$ \\
\hline 8 & $\beta-\mathrm{OH}-\mathrm{Asp}$ & Asp & Hydroxylation & $\mathrm{Fe}^{3+}$ & $\begin{array}{l}\text { Ornibactin, Alterobactin } \\
\mathrm{A} \text { and } \mathrm{B}\end{array}$ \\
\hline 9 & Bpy-Ala & Ala & - & $\mathrm{Ni}^{2+}$ & $\begin{array}{l}\text { Self-assembly, } \\
\text { catalysis }\end{array}$ \\
\hline 10 & Phen-Cys & Cys & - & $\mathrm{Ni}^{2+}$ & Self-assembly \\
\hline 11 & HQ-Ala & Ala & - & $\begin{array}{l}\mathrm{Zn}^{2+} \\
\mathrm{Cu}^{2+}\end{array}$ & $\begin{array}{l}\text { Anchoring, } \\
\text { sensing, catalysis }\end{array}$ \\
\hline 12 & $\beta-\mathrm{SH}-\mathrm{Asp}$ & Asp & Thiolation & $\mathrm{Pb}^{2+}$ & $\begin{array}{l}\text { Peptidic } \\
\text { chelating agent }\end{array}$ \\
\hline
\end{tabular}

${ }^{a}$ Catechol is not derived from an AA. ${ }^{b} \mathrm{~N}^{5}$-acyl- $\mathrm{N}^{5}$-hydroxy-ornithine ditional AAs participate in the first coordination sphere. However, the phosphorylated Tyr directly interacts with the cation without further participation of other residues, thereby demonstrating two different metal-binding modes installed into the peptide. ${ }^{[6]}$ These results show the impact that a single AA modification can have on metal binding.

\subsection{2 $\alpha$-Synuclein}

$\alpha$-Synuclein ( $\alpha$-syn) is an additional example of the effect of phosphorylation on metal-binding properties. ${ }^{[7,8]}$ This well-investigated protein, which makes up a large portion of insoluble fibrils that occur in individuals with Parkinson's disease, undergoes phosphorylation at two sites: Y125 and S129 (serine, Ser). The impact of phosphorylation on fibril formation was examined with the model 14-mer peptide of the C-terminal region of $\alpha$-syn (positions 119-132): Ac- $\underline{D} P \underline{D} N E A \underline{Y E M P} \underline{\mathrm{S} E E G^{[5]}}$ and its phosphorylated analogs pY125 and pS129. The peptides were reacted with $\mathrm{Tb}^{3+}$ ions as they display enhanced luminescence if they are bound near a phosphorylated Tyr and are also sensitive to multidentate coordination environments due to quenching by coordinated water molecules. These properties can therefore be leveraged to gain insight into metal coordination. Spectroscopic data indicated that pY125 exhibits the strongest affinity for $\mathrm{Tb}^{3+}$ with a fivefold lower $K_{D}$ value than $\mathrm{pS} 129$ or its non-phosphorylated counterpart, showing the importance of the location and residue of the phosphorylation site. pY125 was further evaluated on its ability to selectively bind metal ions using ESI-MS. ${ }^{[7]}$ While no complexation was observed with any of the divalent metal ions tested $\left(\mathrm{Ca}^{2+}, \mathrm{Mg}^{2+}, \mathrm{Zn}^{2+}\right.$, $\mathrm{Mn}^{2+}, \mathrm{Co}^{2+}$, and $\mathrm{Cu}^{2+}$ ), the peptide bound $\mathrm{Tb}^{3+}, \mathrm{Fe}^{3+}$, and $\mathrm{Al}^{3+}$ ions, pointing towards a selectivity for trivalent metal ions.

The three peptides underwent a competition experiment on $\mathrm{Fe}^{3+}$ ions where only pY125 was able to complex the metal ion, resulting in a change of its secondary structure. ${ }^{[7]}$ Altogether, these results demonstrate that these naturally occurring modifications affect peptide-metal coordination properties and can establish new binding sites with possible physiological implications through an induced change in secondary protein structure.

\subsubsection{Amyloid- $\beta$}

A similar effect of phosphorylation is found in S8 of the amyloid- $\beta$ (A $\beta)$ peptide, which is prevalent in Alzheimer's disease, and its aggregation upon $\mathrm{Zn}^{2+}$ binding. ${ }^{\text {[9] }} \mathrm{A} \beta$ has a native $\mathrm{Zn}^{2+}$ binding site that binds the metal ion in a $1: 1$ ratio. A model peptide of $\mathrm{A} \beta$ with the sequence Ac-DAEFR $\underline{H} D \underline{S} G Y \underline{E} V \underline{H H} Q K^{[5]}$ $(\mathrm{pA} \beta(1-16))$ that contains a phosphorylated Ser was used to investigate the effect of this PTM. Probing the stoichiometry between $\mathrm{Zn}^{2+}$ and $\mathrm{pA} \beta(1-16)$ revealed the presence of two binding sites with stoichiometries of $1: 1$ and 1:0.5. This occurrence, which was not observed in the non-phosphorylated analog, indicated dimer formation through bridging two peptides with $\mathrm{Zn}^{2+}$ ions. A structural elucidation study revealed that the phosphate-containing binding site hijacked an AA residue from the original binding site, interrupting its completion. In the non-modified peptide, the fragment $E V H H$ binds one $\mathrm{Zn}^{2+}$ ion in a first step, and His at position 6 closes the first coordination sphere. However, the same His in $\mathrm{pA} \beta(1-16)$ is excluded from this binding site by forming the second binding site with pS8. Consequently, the first binding site is completed by residues from another phosphorylated peptide, giving rise to the dimerization event.

\subsection{Cys Oxidation}

\subsubsection{Methanobactin}

Methanobactin is a Cu-binding metallophore (Fig. 2). ${ }^{[10,11]}$ This ribosomally-synthesized and post-translationally modified peptide (RiPP) is produced by methanotrophs, methane-metabolizing bacteria that require elevated intracellular $\mathrm{Cu}$ concentra- 
tions as cofactors in methane oxidation by methane monooxygenases. Methanobactin, whose original sequence is (Leader)$L \underline{C} G S C Y P \underline{C} S C M,{ }^{[5]}$ undergoes extensive PTMs that reshape and enhance its chelating properties and enable exceptionally high $\mathrm{Cu}$ affinities. ${ }^{[11]}$ Among these modifications, two Cys residues (bold and underlined) undergo a rearrangement that includes enzymatic oxidation to form oxazolone-thioamide moieties, each of which binds $\mathrm{Cu}^{+}$bidentatly via their $\mathrm{S}$ and $\mathrm{N}$ atoms. This results in an $\mathrm{N}_{2} \mathrm{~S}_{2}$ binding site with a distorted tetrahedral geometry, which eventually forms a mononuclear complex with an overall association constant in the range of $10^{21} \mathrm{M}$. Noteworthy, such a strong binding cannot be achieved by non-modified, canonical AAs.

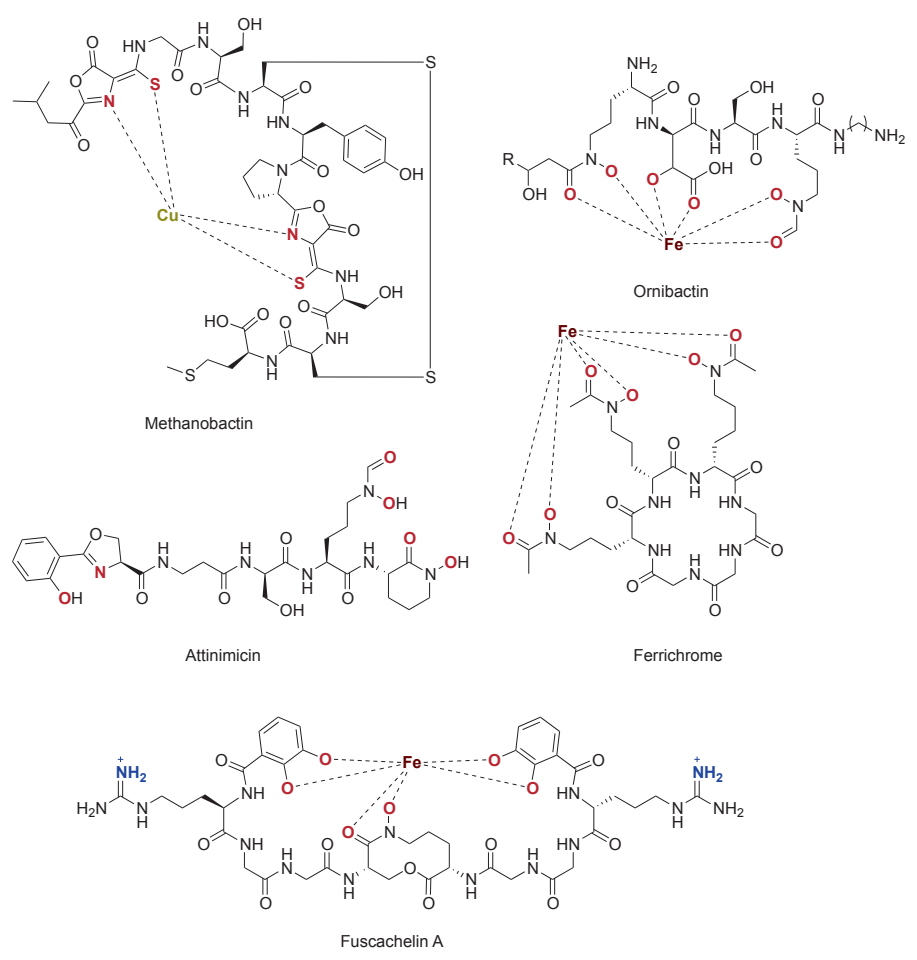

Fig. 2. Examples for naturally occurring, highly-modified peptides for metal coordination: the $\mathrm{Cu}^{+}$metallophore, methanobactin; the $\mathrm{Fe}^{3+}$ siderophores ornibactin, ferrichrome, and fuscachelin A; and the antifungal agent attinimicin. Coordinating atoms are colored in red; groups that serve as second coordination spheres are colored in blue.

\subsection{Peptide Siderophores}

Peptidic iron siderophores are another example of highly modified compounds that enhance selective and potent metalbinding. ${ }^{[12]}$ This class of nonribosomal peptides evolved to supply the microorganism sufficient amounts of essential $\mathrm{Fe}^{3+}$ ions that under aerobic conditions are scarce. These ligands are, therefore, among the strongest binders for $\mathrm{Fe}^{3+}$ ions. These ultrahigh affinities achieved by siderophores are thanks to the unique functional groups that are not found in non-modified peptides and proteins. Three functional groups are repeatedly present as $\mathrm{Fe}^{3+}$ bidentate binders in these siderophores: catecholate, hydroxymate, and $\alpha$-hydroxy carboxylate (Fig. 1, Table 1, compounds 6-8, respectively). ${ }^{[12]}$ While the catechol is not derived from an AA but is introduced to the assembly-line directly as a catechol thioester, the other two binding groups are modified AAs: hydroxymates are products of ornithine (Orn) acylation and hydroxylation and $\alpha$-hydroxy carboxylates of aspartic acid (Asp) hydroxylation. ${ }^{[13]}$

Peptide siderophores can be found linear or cyclic. Examples of such peptides are ornibactin, fuscachelin A, ferrichrome, alterobactin A, and its linear counterpart, alterobactin B (examples in Fig. 2). Alterobactin A demonstrates an extraordinarily high affinity for $\mathrm{Fe}^{3+}$ ions, with a reported $\mathrm{Ka}$ value of $10^{49}-10^{53} \cdot{ }^{[14]}$ This value is one of the highest affinities reported for siderophores today. The siderophores typically bind the metal ion in a distorted octahedral geometry, where each of the three binding groups contributes two coordination bonds. The overall charge of the complex depends on that of the ligand that is in the range of tri- to penta-anionic, resulting in either neutral or negatively charged complexes. To electrostatically stabilize the latter, basic AAs, usually arginine (Arg, R), serve as the second coordination spheres. Noteworthy, metal-binding requires only minor conformational change of the ligands compared to the apo peptides. This exemplifies very well-defined scaffolds that are specifically tuned for coordinating $\mathrm{Fe}^{3+}$ ions. In addition, theoretical calculations for alterobactin A showed that any change in stereochemistry would impair $\mathrm{Fe}^{3+}$ binding, which further underlines the exquisite finetuning these ligands have achieved. ${ }^{[14]}$

\subsection{Peptide Antifungals}

With a remarkable resemblance to peptide siderophores, peptide antifungals are formed by bacteria under symbiotic arrangements with protected fungi. ${ }^{[15]}$ These secondary metabolites contain similar functional groups, mainly but not only the Orn-based hydroxymates. Recently, a new antifungal peptide named attinimicin (Fig. 2) was discovered that shows an iron-dependent activity; only the apo peptide is active, where metal-binding shields its toxicity. ${ }^{[15]}$ While the whole mechanism is still unclear, this peptide binds $\mathrm{Fe}^{3+}$ with an association constant of $10^{19}$, which is dramatically weaker than siderophores. ${ }^{[15]}$ These critical differences in binding constants hint that, unlike other siderophorebased antimicrobial substances, attinimicin does not hijack the precious metal ions nor uses their transmembranal receptors to penetrate the cells.

\section{Artificial Systems}

Proteins and peptides have found many applications in artificial systems for purposes such as catalysis, detection, and the formation of self-assembled structures. As de novo protein design is still a challenging task, ncAAs have been exploited too, to broaden the toolkit and achieve desired functions more readily.

\subsection{Detection of Cys Oxidation}

The amino acid Cys is subjected to a wide range of PTMs; some involve its oxidation that can alter metal binding. Zondlo and Urney probed the effect of Cys oxidation to sulfinic acid (Cys$\mathrm{SO}_{2}^{-}$) on metal-binding in an EF-Hand motif and harnessed this PTM to develop it into a genetically encodable protein tag that is responsive to this particular Cys oxidative modification by giving rise to luminescence in the presence of $\mathrm{Tb}^{3+}$ ions. ${ }^{[16]}$ Short peptides were designed based on the $\mathrm{Ca}^{2+}$ binding calmodulin $(\mathrm{CaM})$ EF-Hand motif, which shows the response to Cys- $\mathrm{SO}_{2}^{-}$formation through enhanced $\mathrm{Tb}^{3+}$ binding. Cys and $\mathrm{Cys}_{-} \mathrm{SO}_{2}^{-}$were systematically placed in the mimetic peptide Ac-DKDA $\underline{\mathbf{C}} G W I S P A E A K$ $\mathrm{NH}_{2}{ }^{\text {[5] }}$ Replacing the native Asp with $\mathrm{Cys}-\mathrm{SO}_{2}^{-}$enabled a tight binding of $\mathrm{Tb}^{3+}$ ions without the loss of function due to similar properties, such as oxygen donating groups and negative charges at physiological $\mathrm{pH}$. This occurred even though $\mathrm{Cys}-\mathrm{SO}_{2}^{-}$has a tetrahedral geometry and not a planar one, like Asp. Furthermore, it was found that the structures of this metal-bound peptide closely resemble the metal-bound native peptide. This undermined the assumption that $\mathrm{Cys}-\mathrm{SO}_{2}{ }^{-}$can replace Asp in this specific peptide. In contrast, incorporating Cys instead of Asp dramatically lowered the binding affinity since the thiol is a smaller functional group that predominantly exists in its protonated form. Interestingly, various Cys-related PTMs, including other oxidation species, did not bind $\mathrm{Tb}^{3+}$ ions within this construct, as reflected by the low fluorescence. Hence, $\mathrm{Tb}^{3+}$ can selectively probe the formation of Cys- $\mathrm{SO}_{2}^{-}$species in this sequence. 


\subsection{Coordination-driven Self-assembly}

A recent work by Song and Yang elegantly demonstrated the utility of a ncAA to promote protein self-assembly.[17] In this work, the authors biosynthetically incorporated three bipyridylAla (bpy-Ala; Fig. 1, Table 1, compound 9 ) residues into an acetyltransferase via site-directed mutagenesis. This AA bears two nitrogens that can act as a ligand for metal ions. Adding $\mathrm{Ni}^{2+}$ ions to these modified proteins was shown to induce well-defined selfassembly of protein subunits through chelation. $\mathrm{Ni}^{2+}$ ions bridged individual subunits by forming $\left[\mathrm{Ni}(\mathrm{bpy}-\mathrm{Ala})_{2}\right]^{2+}$, where each bpy-Ala derives from a separate protein molecule. As the WT protein did not form any higher-ordered structures, it was shown that metal chelation was the main driving force for self-assembly, omitting the difficult task of optimizing the fully proteinogenic AA sequence to achieve the same result. Moreover, manifold assemblies, such as 1D and 2D structures or fibrils, could be generated by variation of the placement of bpy-Ala within the primary sequence, underlining the utility of this strategy. A similar approach was exploited with the phenanthroline (Phen; Fig. 1, Table 1, compound 10) group covalently attached to the surface of a cytochrome $\mathrm{C}$ variant. ${ }^{[18]} \mathrm{A}$ well-defined supramolecular triangle was formed upon $\mathrm{Ni}^{2+}$ addition, where three ions were placed on the edges, bridging three protein molecules.

\subsection{Metal Anchoring and Sensing}

The efficient use of incorporating artificial AAs with optimized metal-binding properties into protein scaffolds was also used to create a metal anchoring site. In a recent study, 2-amino3-(8-hydroxyquinolin-3-yl)propanoic acid (HQ-Ala; Fig. 1, Table 1 , compound 11) was site-specifically incorporated into a protein for selective $\mathrm{Zn}^{2+}$ binding. ${ }^{[19]}$ It was found that only the combination of $\mathrm{Zn}^{2+}$ ions and the mutant yields fluorescence, an effect that the WT protein cannot achieve. Thus, incorporating HQ-Ala into proteins presents an opportunity to harness this property as a fluorescence probe for $\mathrm{Zn}^{2+}$ ions.

\subsection{Catalysis}

The emerging field of developing artificial metalloenzymes takes advantage of the latest technologies that allow to introduce ncAAs by the ribosomal machinery.[4,20] For example, HQ-Ala was also incorporated biosynthetically into an artificial metalloenzyme to bind $\mathrm{Zn}^{2+}$ and $\mathrm{Cu}^{2+}$ ions. ${ }^{[21]}$ The new system was further exploited to execute various reactions, including hydrolysis, hydration, and alkylation, depending on the metal ion.

\subsection{Heavy Metal Detoxification}

Chelation therapy, which is the administration of a drug to treat metal poisoning, is the only medicinal solution for handling poisonous metals, such as mercury $(\mathrm{Hg})$, cadmium $(\mathrm{Cd})$, arsenic $(\mathrm{As})$, and lead $(\mathrm{Pb}) \cdot{ }^{[22,23]}$ The chelating agents used in the clinic are all small molecules that suffer from various drawbacks, mainly poor metal selectivity that results in depletion of essential metals upon treatment. Although nature utilizes peptides and proteins to control metal poisoning, ${ }^{[24]}$ and it is already established that peptides and artificial AAs can achieve excellent metal affinity and selectivity, this potential application is overlooked.[25]

We recently explored a family of cyclic tetrapeptides for their ability to detoxify $\mathrm{Pb}^{2+}$ ions ${ }^{[26]}$ as one of the most harmful metals to human health.[27] At first, the peptides were composed of only proteinogenic coordinating AAs: Cys, Asp, Met, and His, where one peptide excelled to a greater extent recovering $\mathrm{Pb}$-poisoned human cells. The peptide bears the sequence $c y c-[C \beta A D \beta A]$ (Fig. 3a) and outperforms the benchmark drugs in both efficacy and toxicity level. However, its holo solubility is not sufficient. We also aimed at enhancing its affinity and metal selectivity. Mercaptoaspartic acid (SAsp (sD); Fig. 1, Table 1, compound 12) was developed for native chemical ligation ${ }^{[28,29]}$ yet was never in- vestigated for its coordination properties. Inspired by $\beta$-OH-Asp in siderophores, we envisioned that this AA that mimics the chelating agent dimercaptosuccinic acid (DMSA; Fig. 3c) could also serve as an excellent coordinating residue of $\mathrm{Pb}^{2+}$ ions. This is due to the preference of these toxic ions to bind both thiolates and carboxylates so that upon binding, a stabilizing five-membered ring is formed. We, therefore, synthesized a peptide analog with the sequence cyc-[(SD) $\beta \mathrm{AD} \beta \mathrm{A}]$ (Fig. 3b), replacing Cys with SAsp. This peptide was found to be superior to the Cys-containing peptide, with improved characteristics in every tested aspect: higher potency in recovering $\mathrm{Pb}$-contaminated cells, lack of toxicity, enhanced affinity, and metal selectivity. ${ }^{[26]}$ It was also found stable toward oxidation and degradation for $48 \mathrm{~h}$ in human blood serum, while the Cys-containing peptide underwent oxidation in a similar setup. ${ }^{[26]}$ These results indicate the great promise that ncAAs also hold toward pharmaceutical purposes. (a)

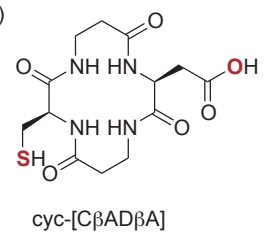

(b)

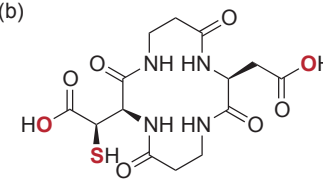

cyc-[sD $\beta A D \beta A]$ (c)

$$
\underbrace{\mathrm{S} H}_{\text {DMSA }}
$$

Fig. 3. Peptides cyc- $[C \beta A D \beta A]$ (a) and cyc- $[s D \beta A D \beta A]$ (b) that were developed for selective $\mathrm{Pb}$-detoxification; the benchmark drug DMSA as one of the two medications to treat $\mathrm{Pb}$-poisoning (c).

\section{Conclusions and Outlook}

The examples presented herein manifest the vast potential of ncAAs to allow polypeptides to attain strong metal-binding properties that cannot be achieved with proteinogenic residues. Natural systems rely on dynamic metal coordination that enables fast binding and release of the ion(s) upon a chemical or physical trigger. In addition, as ribosomal polypeptides are composed of the same proteinogenic AAs but serve a wide array of properties and functionalities, an ultra-strong metal-binding by a canonical AA could negatively influence many biomolecules that should not have interacted with metals. As some systems still require more potent and robust metal-binding properties, nature overcame this challenge by the modifications described above.

Inspired by these abilities, and while observing the artificial systems that implement ncAAs for various purposes, we learn about the multiple options latent with ncAA incorporation. Whether for achieving metal selectivity or outstanding affinity, inducing new functionality by incorporating non-native metal ions, or introducing non-essential ions to natural systems, all can be performed elegantly with the aid of ncAAs.

\section{Acknowledgments}

We thank Prof. R. K. O. Sigel and the Department of Chemistry of the University of Zurich for their hospitality and generous support. The Swiss National Science Foundation (SNSF, M. S. S./PZ00P2_179818) and the Forschungskredit of the University of Zurich (L. S./K-73521-11-01) are kindly acknowledged for their financial support.

Received: April 6, 2021

[1] A. Rosato, Y. Valasatava, C. Andreini, Int. J. Mol. Sci. 2016, 17, 671, https://doi.org/10.3390/ijms17050671

[2] H. Yu, S. Yu. Noskovb, B. Roux, Proc. Natl. Acad. Sci. USA 2010, 107, 20329, https://doi.org/10.1073/pnas.1007150107

[3] E. T. Yukl, C. M. Wilmot, Curr. Opin. Chem. Biol. 2012, 16, 54, https://doi.org/10.1016/j.cbpa.2012.02.010 
[4] P. J. Almhjell, J. H. Mills, Curr. Opin. Struct. Biol. 2018, 51, 170, https://doi.org/10.1016/j.sbi.2018.06.001

[5] AAs in bold are susceptible to undergo modifications, and underlined AAs participate in metal-binding.

[6] G. S. Baldwin, M. F. Bailey, B. P. Shehan, I. Sims, R. S. Norton, Biochem. J. 2008, 416, 77, https://doi.org/10.1042/BJ20081059

[7] L. L. Liu, K. J. Franz, J. Biol. Inorg. Chem. 2007, 12, 234, https://doi.org/10.1007/s00775-006-0181-y

[8] N. González, T. Arcos-López, A. König, L. Quintanar, M. Menacho Márquez, T. F. Outeiro, C. O. Fernández, J. Neurochem. 2019, 150, 507, https://doi.org/10.1111/jnc.14721

[9] A. A. Kulikova, P. O. Tsvetkov, M. I. Indeykina, I. A. Popov, S. S. Zhokhov, A. V. Golovin, V. I. Polshakov, S. A. Kozin, E. Nudler, A. A. Makarov, Mol. Biosyst. 2014, 10, 2590, https://doi.org/10.1039/C4MB00332B

[10] L. M. K. Dassama, G. E. Kenney, A. C. Rosenzweig, Metallomics 2017, 9, 7, https://doi.org/10.1039/C6MT00208K

[11] G. E. Kenney, L. M. K. Dassama, M. E. Pandelia, A. S. Gizzi, R. J. Martinie, P. Gao, C. J. DeHart, L. F. Schachner, O. S. Skinner, S. Y. Ro, X. Zhu, M. Sadek, P. M. Thomas, S. C. Almo, J. M. Bollinger, C. Krebs, N. L. Kelleher, A. C. Rosenzweig, Science 2018, 359, 1411, https://doi.org/10.1126/science.aap9437

[12] H. Drechsel, G. Jung, J. Pept. Sci. 1998, 4, 147, https://doi.org/10.1002/ (SICI) 1099-1387(199805)4:3<147::AID-PSC136>3.0.CO;2-C

[13] C. D. Hardy, A. Butler, J. Biol. Inorg. Chem. 2018, 23, 957, https://doi.org/10.1007/s00775-018-1584-2

[14] R. T. Reid, D. H. Livet, D. J. Faulkner, A. Butler, Nature 1993, 366, 455, https://doi.org/10.1038/366455a0

[15] T. T. H. Fukuda, E. J. N. Helfrich, E. Mevers, W. G. P. Melo, E. B. van Arnam, D. R. Andes, C. R. Currie, M. T. Pupo, J. Clardy, ACS Cent. Sci. 2021, 7, 292, https://doi.org/10.1021/acscentsci.0c00978.

[16] A. R. Urmey, N. J. Zondlo, Free Radic. Biol. Med. 2020, 152, 166, https://doi.org/10.1016/j.freeradbiomed.2020.02.020

[17] M. Yang, W. J. Song, Nat. Commun. 2019, 10, 1, https://doi.org/10.1038/s41467-019-13491-w

[18] R. J. Radford, F. A. Tezcan, J. Am. Chem. Soc. 2009, 131, 9136, https://doi.org/10.1021/ja9000695
[19] H. S. Lee, G. Spraggon, P. G. Schultz, F. Wang, J. Am. Chem. Soc. 2009, 131, 2481, https://doi.org/10.1021/ja808340b

[20] I. Drienovská, G. Roelfes, Nat. Catal. 2020, 3, 193 https://doi.org/10.1038/s41929-019-0410-8

[21] I. Drienovská, R. A. Scheele, C. Gutiérrez de Souza, G. Roelfes, ChemBioChem 2020, 21, 3077, https://doi.org/10.1002/cbic.202000306

[22] S. J. S. Flora, Al Ameen J. Med. Sci. 2009, 2, 4.

[23] J. Aaseth, O. Andersen, 'Chelation Therapy in the Treatment of Metal Intoxication', 2016.

[24] C. Cobbett, P. Goldsbrough, Annu. Rev. Plant Biol. 2002, 53, 159, https://doi.org/10.1146/annurev.arplant.53.100301.135154

[25] L. Sauser, M. S. Shoshan, J. Inorg. Biochem. 2020, 212, 111251, https://doi.org/10.1016/j.jinorgbio.2020.111251

[26] T. A. Mohammed, C. M. Meier, T. Kalvoda, M. Kalt, L. Rulíšek, M. S. Shoshan, Angew. Chem. Int. Ed. 2021, https://doi.org/10.1002/anie.202103217

[27] H. Needleman, Аnпи. Rev. Med. 2004, 55, 209 https://doi.org/10.1146/annurev.med.55.091902.103653

[28] R. E. Thompson, B. Chan, L. Radom, K. A. Jolliffe, R. J. Payne, Angew Chem. Int. Ed. 2013, 52, 9723, https://doi.org/10.1002/anie.201304793

[29] X. Guan, M. R. Drake, Z. Tan, Org. Lett. 2013, 15, 6128, https://doi.org/10.1021/ol402984r

\section{License and Terms}

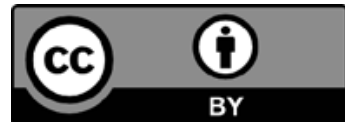

This is an Open Access article under the terms of the Creative Commons Attribution License CC BY 4.0. The material may not be used for commercial purposes.

The license is subject to the CHIMIA terms and conditions: (http:// chimia.ch/component/sppagebuilder/?view=page\&id=12).

The definitive version of this article is the electronic one that can be found at https://doi.org/10.2533/chimia.2021.530 